\title{
Letters and comments
}

Contributors to this section are asked to make their comments brief and to the point. Letters should comply with the instructions to authors at http://www.rcseng.ac.uk/publications/ annals/authorinstructions.html. Tables and figures should only be included if absolutely essential and no more than five references should be given. The editor reserves the right to shorten letters and subedit contributions to ensure clarity.

\section{COMMENT ON}

\section{doi $10.1308 / 003588407 \times 232143$}

I Singh, N Panesar, P Ng. How to avoid a second 10-mm port during laparoscopic appendicectomy and laparoscopic hernia repair. Ann $R$ Coll Surg Eng/ 2007; 89: 815-24

\section{doi $10.1308 / 003588408 \times 317986$}

\section{A cautionary note}

\section{PAUL BEVIS}

Department of Surgery, Great Western Hospital, Swindon, UK

\section{CORRESPONDENCE TO}

Paul Bevis, Department of Surgery, Great Western Hospital, Marlborough Road, Swindon SN3 6BB, UK

E: paul_bevis@hotmail.com

Having read this article on the avoidance of a second 10$\mathrm{mm}$ port in laparoscopic appendicectomy, I would recommend some caution. This was a technique I previously employed until, during one operation using this approach, the appendix became divided during its passage through the port. This occurred despite having visualised the end of the appendix all the way out of the port and necessitated retrieval of the remaining appendix and further washout. Although the patient involved had no deleterious outcome, this led to a change in my practice.

Now, in order to allow appendicectomy using a single 10mm port, I would recommend inserting a collection bag with a tail via the $10-\mathrm{mm}$ port. The bag can be held open using the tension of the tail against the $10-\mathrm{mm}$ port and one grasper whilst the appendix is placed in the bag. The bag can then be retrieved using the tail at the end of the procedure when withdrawing the 10 -mm port. I have found this to be easy to perform and it allows the surgeon greater peace of mind.

\section{COMMENT ON}

doi 10.1308/003588407X209356

P Guyver, K Vanstone, T Nowlan, K Trimble. Drug safety with regard to intra-operative local anaesthetic administration. Ann $R$ Coll Surg Eng/ 2007; 89: 725-31

\section{doi $10.1308 / 003588408 \times 318002$}

\section{Viewing the expiry date on clear plastic vials}

J HORWOOD, B RAMANAND

Department of General Surgery, Glan Clwyd Hospital, Rhyl, Denbighshire, UK

\section{CORRESPONDENCE TO}

J Horwood, Department of General Surgery, Glan Clwyd Hospital, Rhyl, Denbighshire LL18 5UJ, UK

E: tipper111@aol.com

We agree with the observation about the difficulty in verifying the expiry date on clear plastic vials of local anaesthetic, particularly under the bright lights of the operating theatre. We have overcome this problem by dipping the end of the vials in povidone iodine, which is readily available in theatre, thus negating the requirement for, and cost of, permanent marker pens.

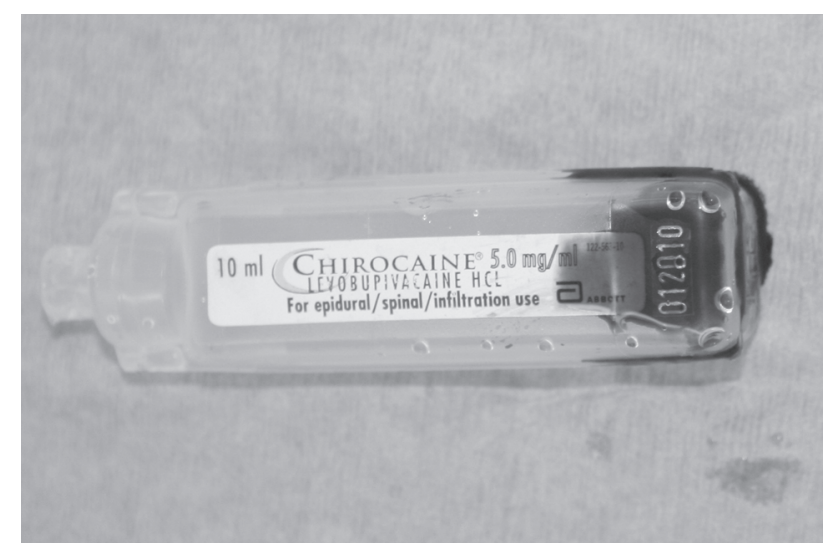

Figure 1 The 'dipping' technique. 